\title{
ANÁLISE DA PRESENÇA DA VARIAÇÃO LINGUÍSTICA EM LIVROS DIDÁTICOS DOS ANOS FINAIS DO ENSINO FUNDAMENTAL
}

\author{
Aléxia Islabão dos Santos ${ }^{1}$ \\ Kleber Eckert ${ }^{2}$
}

\begin{abstract}
Resumo: No presente artigo, realiza-se uma análise da coleção de livros didáticos para os anos finais do Ensino Fundamental intitulada Tecendo Linguagens: língua portuguesa (ARAÚJO; OLIVEIRA, 2018) com o objetivo de demonstrar como a variação linguística é abordada. A metodologia do trabalho consistiu na leitura de todos os capítulos de cada livro pertencente à coleção e na descrição da forma como esse conteúdo é abordado por ela. A análise orientou-se pelos estudos de Bagno (2007), que serviram como fundamentação teórica base para este trabalho. Além disso, o artigo também está embasado em mais autores da área da sociolinguística, como Zilles e Faraco (2017), Basso e Ilari (2012), Coelho et al. (2015), Bagno (2013), entre outros. Como resultados, pode-se destacar a análise detalhada da forma como os livros didáticos escolhidos abordam de forma teórica e prática conceitos pertinentes à variação linguística, além de uma análise geral em que são apontados os aspectos desse tema que foram ou não abordados pela coleçáo.
\end{abstract}

Palavras-chave: livros didáticos; língua portuguesa; ensino fundamental; variação linguística.

\section{ANALYSIS OF THE PRESENCE OF LINGUISTIC VARIATION IN TEXTBOOKS FROM THE FINAL YEARS OF ELEMENTARY SCHOOL}

\begin{abstract}
In this article, an analysis of the collection of textbooks for the final years of Elementary School entitled Tecendo Linguagens: língua portuguesa (ARAÚJO; OLIVEIRA, 2018) is carried out in order to demonstrate how linguistic variation is approached. The methodology of the work consisted of reading all the chapters of each book belonging to the collection and describing how this
\end{abstract}

1 Graduanda em Letras - Português pelo Instituto Federal de Educação, Ciência e Tecnologia do Rio Grande do Sul (IFRS) - Campus Bento Gonçalves. Email: alexiaislabao@gmail.com

2 Doutor em Letras pela Universidade de Caxias do Sul (UCS) e professor do Instituto Federal de Educação, Ciência e Tecnologia do Rio Grande do Sul (IFRS) - Campus Bento Gonçalves. Email: kleber.eckert@bento.ifrs.edu.br 
content is approached by it. The analysis was guided by the studies by Bagno (2007), which served as the theoretical basis for this work. In addition, the article is also based on more authors in the field of sociolinguistics, such as Zilles and Faraco (2017), Basso and Ilari (2012), Coelho et al. (2015), Bagno (2013), among others. As a result, we can highlight the detailed analysis of how the chosen textbooks approach in a theoretical and practical way concepts relevant to linguistic variation, in addition to a general analysis in which the aspects of this theme that were or were not addressed by the collection are pointed out.

Keywords: textbooks; portuguese language; elementary school; linguistic variation.

\section{Introdução}

O presente trabalho tem por objetivo realizar uma análise de uma coleção de livros didáticos para os anos finais do Ensino Fundamental, a fim de verificar a presença de conteúdos relacionados à variação linguística. Para isso, foi escolhida a coleção "Tecendo Linguagens: língua portuguesa”, de Lucy Aparecida Melo Araújo e Tânia Amaral Oliveira, publicada em 2018. Como o foco está nos anos finais do Ensino Fundamental, foram analisados apenas os livros de sexto a nono ano. Para a análise, utilizaram-se os livros destinados aos professores.

Todos os livros didáticos do professor pertencentes a essa coleção contam com um manual em formato de "U" que cobre a lateral e a parte inferior das páginas. Nele, o professor encontra as competências gerais, as competências específicas de Linguagens e de Língua Portuguesa e as habilidades da BNCC trabalhadas em cada capítulo e subcapítulo (veja mais sobre a BNCC na fundamentação teórica). Nele também estâo presentes orientaçôes ao professor sobre como abordar as temáticas do livro, sugestóes de atividades para executar com os alunos, complementos sobre atividades contidas no livro, indicaçôes de leituras, entre outros. Ou seja, tudo aquilo que pode facilitar a compreensão do professor acerca do livro e proporcionar a ele o máximo aproveitamento do material disponível.

A metodologia utilizada para a análise da coleção se deu através da leitura atenta e integral de cada livro e da descrição de suas abordagens sobre os conteúdos e exercícios. A análise da coleção inspirou-se no roteiro para análise de livros didáticos sugerido por Bagno (2007, p. 125-139). As perguntas contidas no roteiro do sociolinguista encontram-se na fundamentação teórica apresentada a seguir. A fundamentaçáo teórica abrange alguns tópicos da sociolinguística - como a variaçáo linguística, as variedades do português e o preconceito linguístico - e das normas que regem a elaboração de materiais didáticos. Nela, esses tópicos são descritos e explicados de forma breve e objetiva com base em autores da área. Dessa forma, garante-se que o leitor seja previamente apresentado aos assuntos que seráo vistos na sequência durante a análise.

Conforme será possível perceber mais adiante, durante a análise foi possível encontrar diversas referências aos conceitos de variação linguística dentro da coleção. Assim sendo, se a análise de cada um dos quatro livros fosse descrita de forma detalhada, este artigo se estenderia mais que o desejado. Portanto, apenas um dos livros, o livro destinado ao sexto ano, foi selecionado para apresentaçáo 
da análise detalhada. A justificativa para a escolha desse livro se dá pelo fato de que ele apresenta em seu conteúdo um capítulo destinado especialmente à variação linguística, muito relevante para este trabalho. Os outros três livros também foram inteiramente analisados. A partir dessas análises, elaborou-se uma síntese dos aspectos considerados principais para compor o artigo.

Para garantir a organização e a devida separaçáo de cada assunto, na análise detalhada do livro de sexto ano, os títulos estão divididos de modo a representar os capítulos analisados conforme constam no livro. Em um título separado, encontra-se a análise sintetizada dos outros três livros. Durante a análise, estabelecese uma relaçáo entre a forma como o conteúdo é trabalhado pelo livro didático e a fundamentação teórica apresentada inicialmente. Ao final, apresentam-se as consideraçôes finais obtidas com a análise dos livros didáticos, uma tabela de análise geral da presença dos conteúdos de variação linguística na coleção e as referências utilizadas na elaboraçáo deste trabalho.

\section{Fundamentaçáo Teórica}

Como o tema deste trabalho é a variação linguística em uma coleção de livros didáticos, iniciam-se as reflexôes nessa seara. A variação linguística é um ramo da Sociolinguística, "área da Linguística que estuda a relação entre a língua que falamos e a sociedade em que vivemos" (COELHO et al., 2015, p. 12). De acordo com Coelho et al. (2015, p. 13), "cada grupo social apresenta características no seu falar condicionadas por sua origem, sua idade, sua escolaridade, entre outros". Ou seja, isso significa que "as pessoas à nossa volta falam de diferentes maneiras". Em síntese, "a língua varia, e essa variação decorre de fatores que estão presentes na sociedade [...]. A Sociolinguística se ocupa desses fatores".

Bellini e Sousa (2014, p. 216) afirmam que até hoje "os professores ainda limitam o ensino de Língua Portuguesa às aulas de gramática normativa, cuja função é corrigir o português considerado errado, ensinando nomenclatura gramatical". Nessa linha, Zilles e Faraco (2017, p. 183-184) defendem que "a cultura do certo-errado que hoje impera precisa ser criticamente avaliada e banida da escola e da sociedade por ser reducionista, artificial, contrária à realidade das práticas de uso variável da língua e por alimentar e justificar o preconceito linguístico". Para esses autores, existe uma "distância" e uma "incongruência entre o prescrito e o efetivamente usado pelos falantes" (ZILLES; FARACO, 2017, p. 177) e, por isso, "a variação linguística precisa estar sempre presente no ensino da língua" (ZILLES; FARACO, 2017, p. 176). O estudo da variação linguística visa incluir no aprendizado dos alunos as diversas possibilidades de variedades na língua e eliminar o preconceito linguístico.

Na obra "Nada na língua é por acaso", Marcos Bagno problematiza a forma como alguns livros didáticos costumam abordar a variação linguística. Para ele, um dos principais problemas encontrados é a "tendência a tratar da variaçáo linguística como sinônimo de variedades regionais, rurais ou de pessoas náo escolarizadas" (BAGNO, 2007, p. 120). Ou seja, como se a variação linguística fosse um fenômeno 
que caracterizasse "somente os falantes rurais, analfabetos e pobres" (BAGNO, 2007, p. 125). O que por extensão leva os alunos a entender, de forma errônea, que "os falantes urbanos escolarizados usam a língua do modo "correto" e que em seu uso não existe variação" (BAGNO, 2007, p. 120).

A variedade utilizada por esses falantes urbanos escolarizados chama-se norma culta. De acordo com Zilles e Faraco (2017, p. 19), "norma culta designa o conjunto das características linguísticas do grupo de falantes que se consideram cultos". Em nossa sociedade, entende-se por culto o grupo "tipicamente urbano, de elevado nível de escolaridade e que faz amplo uso dos bens da cultura escrita”. Esses mesmos autores destacam que "a norma culta falada em nosso país é um conjunto de variedades", ou seja, não há uma única maneira de falar na norma culta (ZILLES; FARACO, 2017, p. 186). Isso vai ao encontro do que foi dito no parágrafo anterior, comprovando o que diz Bagno (2007) sobre a existência de variação tanto nas falas rurais quanto nas falas urbanas.

Outro ponto criticado por Bagno (2007, p. 129) é que a variedade de falantes urbanos e escolarizados é considerada prestigiada, causando uma "ilusão de que eles se comportam linguisticamente de acordo com as prescriçóes da gramática normativa”, também conhecida por norma-padrão. A norma-padrão designa "o conjunto de preceitos estipulados no esforço homogeneizador do uso em determinados contextos" (ZILLES; FARACO, 2017, p. 19), ou seja, um conjunto de regras que visa estipular um padrão para o uso da língua em certas situaçóes. Nesse sentido, ela é um "modelo idealizado construído para fins específicos" (ZILLES; FARACO, 2017, p. 19).

Por ser esse modelo idealizado é que Bagno (2007) afirma ser uma ilusão pensar que a norma culta prestigiada está de acordo com a norma-padrão. Para o autor, a norma-padrão "não é a língua de ninguém" (BAGNO, 2007, p. 131). Bagno (2017, p. 131) ainda divide o português brasileiro em três: norma-padrão; conjunto de variedades estigmatizadas; e conjunto de variedades prestigiadas, sendo que cada um dos conjuntos caracteriza "grupos sociais específicos". O autor ainda reforça: "não existe um grupo social que fale mais 'certo' do que o outro" (BAGNO, 2007, p. 130). Por isso, o ensino de língua "não pode ser exclusivamente o ensino da norma-padrão, nem só o ensino da norma culta” (ZILLES; FARACO, 2017, p. 176).

Coelho et al. (2015, p. 142) concordam com Bagno ao afirmar que, "do ponto de vista linguístico, qualquer uma das variedades linguísticas está correta". "O valor social das formas linguísticas não é intrínseco a elas, mas é resultado da avaliação social atribuída a seus usuários" (COELHO et al., 2015, p. 136-137). Para esses autores, "qualquer língua comporta diferentes variedades que devem ser entendidas linguisticamente e respeitadas, sejam elas usadas por um indivíduo escolarizado ou por um indivíduo analfabeto, sejam elas de variedades cultas ou de variedades" estigmatizadas (COELHO et al., 2015, p. 137-138). É papel da escola ser "porta-voz da luta contra o preconceito linguístico", que causa atitudes de "intolerância e exclusão social" (COELHO et al., 2015, p. 147). "O respeito às 
variedades linguísticas e o combate ao estigma e ao preconceito devem fazer parte do objetivo maior de todas as aulas de língua portuguesa e de todos os conteúdos relativos à norma culta da língua" (COELHO et al., 2015, p. 161).

Além disso, segundo Bagno (2007, p. 126-128), outro aspecto da variação linguística que está ausente nos livros didáticos é o plurilinguismo brasileiro. Para o autor, esse plurilinguismo "sempre foi silenciado" (BAGNO, 2007, p. 128), levando os cidadãos a acreditarem em um falso monolinguismo no país, em que "ser brasileiro é sinônimo de ser falante do português" (BAGNO, 2007, p. 126). No entanto, junto com o português brasileiro coexistem mais cerca de 210 outras línguas, sendo cerca de 190 delas de origem indígena e cerca de 20 delas de origem europeia e asiática. No Brasil se encontram imigrantes de várias regiōes do mundo, como Alemanha, Itália, Japão, Coréia, China, Líbano, Polônia, Ucrânia, entre outros. Esses imigrantes contribuíram e contribuem para a pluralidade de línguas existente no país. Para Zilles e Faraco (2017, p. 185), "é fundamental para o ensino produtivo da Língua Portuguesa na escola o reconhecimento e a valorização de nossa realidade multilíngue" e do "impacto que o contato entre essas línguas e o Português teve e tem para o estabelecimento das variedades hoje existentes".

Contudo, atualmente, os materiais didáticos precisam adequar-se a diversos parâmetros e normas para serem aprovados e poderem ser utilizados nas escolas. Os livros didáticos analisados neste trabalho são bastante recentes, o que significa que passaram por esses estágios, então espera-se que sua qualidade seja superior aos pontos fracos apontados por Bagno (2007). A coleçáo de livros selecionada foi aprovada pelo Programa Nacional do Livro Didático (PNLD) 2020, projeto "por meio do qual o Ministério da Educação (MEC) avalia, compra e distribui obras destinadas ao ensino de diferentes disciplinas que compóem o currículo do Ensino Fundamental" (BAGNO, 2007, p. 119). De acordo com Bagno (2007, p. 119), esse processo de avaliação envolve uma "grande quantidade de linguistas e educadores que vem fornecendo uma importante contribuição para a elaboração de uma política linguística exercida por meio do livro didático". Segundo o autor, desde a implementação do PNLD, os livros didáticos de português deram um grande salto em sua qualidade.

Porém, esse mesmo autor, em obra mais recente (BAGNO, 2013, p. 11) afirma que, na perspectiva da linguística contemporânea, o tratamento dado à variação linguística "está longe de ser satisfatório". Isso ocorre até mesmo em coleçôes de livros didáticos bem avaliadas pelo PNLD (na obra, o autor se refere ao PNLD 2008). Para o autor, no que diz respeito à parte da obra que trata dos "conhecimentos linguísticos (eixo em que está incluída a abordagem didática da variação linguística) ainda impera uma perspectiva de ensino conservadora e tradicionalista" (BAGNO, 2013, p. 12). A presente análise, sobre um livro aprovado pelo PNLD mais de dez anos depois da fala de Bagno (2013), se propóe a observar se ocorreram mudanças nesse sentido.

A coleção de livros didáticos escolhida também está alinhada com a Base Nacional Comum Curricular (BNCC), "documento que regulamenta quais são 
as aprendizagens essenciais a serem trabalhadas" pelas redes de ensino públicas e privadas na Educação Básica (INSTITUTO AYRTON SENNA, 2020, online). Nesse documento, reúnem-se habilidades que envolvem o ensino e aprendizagem da variação linguística. Dessas habilidades, duas se destacam ao entrar em consonância com o objetivo deste artigo, são elas: EF69LP55: "reconhecer as variedades da língua falada, o conceito de norma-padráo e o de preconceito linguístico" (BRASIL, 2018, p. 161); e EF69LP56: "fazer uso consciente e reflexivo de regras e normas da norma-padrão em situaçóes de fala e escrita nas quais ela deve ser usada" (BRASIL, 2018, p. 161).

Além disso, a coleção também deve estar de acordo com os Parâmetros Curriculares Nacionais (PCN). Esses parâmetros são um "conjunto de documentos que tem como objetivo subsidiar a elaboração do currículo do Ensino Fundamental e Médio no Brasil, visando a formação da cidadania do aluno" (COELHO et al., 2015, p, 135-136). Em suas concepções em relação às práticas com a linguagem, os PCNs consideram:

I. as situações reais de interação são condição para que se dê o ensino da língua, já que a língua funciona para as pessoas interagirem socialmente; II. a língua é heterogênea, historicamente situada, estando sujeita a variaçôes e mudanças; III. o trabalho pedagógico deve contemplar, de maneira articulada, usos linguísticos (ouvir-falar, ler-escrever) e reflexão sobre a língua; IV. o uso da língua deve ser adequado aos propósitos comunicativos e demandas sociais; V. deve-se combater o preconceito linguístico; e VI. a norma culta deve ter lugar garantido na escola, mas náo deve ser a única norma privilegiada no processo de conhecimento linguístico proporcionado ao aluno. (COELHO et al., 2015, p. 138).

O desenvolvimento da análise proposta por este artigo foi inspirado no roteiro de análise de livros didáticos sugerido por Bagno (2007, p. 125-139). O roteiro do sociolinguista propóe dez questôes norteadoras, conforme descrição a seguir:

1. O livro didático trata da variação linguística?

2. O livro didático menciona de algum modo a pluralidade de línguas que existe no Brasil?

3. O tratamento se limita às variedades rurais e/ou regionais?

4. O livro didático apresenta variantes características das variedades prestigiadas (falantes urbanos, escolarizados)?

5. O livro didático separa a norma-padrão da norma culta (variedades prestigiadas) ou continua confundindo a norma-padrão com uma variedade real da língua?

6. O tratamento da variação no livro didático fica limitado ao sotaque e ao léxico, ou também aborda fenômenos gramaticais?

7. O livro didático mostra coerência entre o que diz nos capítulos dedicados à variação linguística e o tratamento que dá aos fatos de gramática? $\mathrm{Ou}$ continua, nas outras seçóes, a tratar do "certo" e do "errado"?

8. O livro didático explicita que também existe variação entre fala e escrita, ou apresenta a escrita como homogênea e a fala como lugar do erro?

9. O livro didático aborda o fenômeno da mudança linguística? Como? 
10. O livro didático apresenta a variação linguística somente para dizer que o que vale mesmo, no fim das contas, é a norma-padrão? (BAGNO, 2007, p. 125- 139)

Utilizando as questóes acima como base, foi desenvolvida uma tabela síntese com os aspectos considerados mais relevantes mencionados por Bagno (2007). Nessa tabela, é possível marcar sim ou não quando o livro didático aborda, ou deixa de abordar, algum desses tópicos. Essa tabela pode ser encontrada nas consideraçóes finais deste artigo. O próximo título apresenta os resultados obtidos com a análise. Ele subdivide-se em dois subtítulos menores dedicados, primeiro, à análise do livro de sexto ano e, segundo, à síntese da análise dos livros de sétimo a nono ano.

\section{Análise da Coleçáo}

Os próximos subtítulos apresentam a análise realizada com os livros didáticos pertencentes à coleção selecionada. Para o livro de sexto ano, a análise foi detalhada em um subtítulo específico em que se encontram seçóes para representar cada capítulo analisado. Para os livros de sétimo a nono ano, a síntese da análise encontrase reunida sob o mesmo subtítulo.

\subsection{Sexto Ano}

O primeiro livro analisado destina-se ao sexto ano do Ensino Fundamental. Esse livro divide-se em oito capítulos. A primeira menção à variação linguística ocorre no capítulo três. Depois, outros conceitos que concernem ao mesmo tema são encontrados nos capítulos quatro, seis, sete e oito. Portanto, nota-se que a variaçáo linguística se faz presente em quase todos os capítulos da obra.

\subsubsection{Capítulo 3: da escola que temos à escola que queremos}

Dentro do capítulo 3, o subcapítulo "reflexão sobre o uso da língua" apresenta em seu início o título "Variedade Linguística", a fim de deixar claro aos alunos e professores que aquele tema será o foco do momento. No manual em "U", na lateral da página, aparece que nesse subcapítulo será trabalhada a habilidade da BNCC EF69LP55, que visa "reconhecer as variedades da língua falada, o conceito de norma-padrão e o de preconceito linguístico" (BRASIL, 2018, p. 161).

O título começa com uma atividade que retoma um texto lido anteriormente. No texto, do gênero crônica e intitulado "na escola", uma professora faz uma votação com seus alunos para decidir se ela poderia vestir calça comprida em sala de aula. Como a narrativa tenta demonstrar a linguagem dos alunos, aparecem nas falas deles gírias e variaçóes linguísticas não pertencentes à norma culta. Para ilustrar melhor, abaixo foram destacados alguns exemplos retirados do texto:

- Porque minissaia é muito mais bacana.

[...]

- Pra mim tanto faz. 


\section{$[\ldots]$ \\ - Ah, cada um na sua. \\ [...] \\ — Uniforme é papo-furado. \\ $[\ldots]$ \\ - A senhora vem de calça comprida, e a gente aparecemos de qualquer jeito. (ARAÚJO, OLIVEIRA, 2018a, p. 85-86, grifo nosso)}

$\mathrm{Na}$ atividade, pede-se ao aluno que observe a maneira como um dos personagens do texto expôs sua opinião para depois responder às questôes (a) e (b). Antes das perguntas, está destacada a frase "a senhora vem de calça comprida, e a gente aparecemos de qualquer jeito" (ARAÚJO, OLIVEIRA, 2018a, p. 88, grifo do autor). Logo, podemos perceber que o livro aborda um fenômeno gramatical relativo à concordância verbal. Isso é um aspecto positivo do ponto de vista de Bagno (2007) em sua proposta de roteiro de análise de livros didáticos, pois o tratamento da variação não está limitado somente ao sotaque e ao léxico.

Para a frase destacada, o livro propóe duas questôes: (a) "a construção destacada no trecho está de acordo com as regras gramaticais? Por quê?", cuja resposta esperada indicada pelo livro é "não, pois o sujeito (a gente) está no singular e o verbo (aparecemos) no plural"; e (b) "construçóes como essa em destaque podem aparecer na fala das pessoas quando elas se comunicam? Por que você acha que isso acontece?" (ARAÚJO, OLIVEIRA, 2018a, p. 88), cuja resposta o livro indica que será pessoal.

Em relação à questão (b), no manual em "U" há uma orientação para o professor, que indica que ele "acolha as hipóteses dos alunos" e explique a eles alguns conceitos importantes da variação linguística. Nesses conceitos, podemos perceber aspectos apontados por Bagno (2007) como de grande importância para o estudo da variação linguística, como: as diferentes variedades da língua, que podem ser prestigiadas ou estigmatizadas; a dinamicidade da língua; e a diferença entre variedade prestigiada e o conceito de norma-padrão. Nessa orientação, afirma-se que todas as variedades - suas maneiras de falar e de escrever — são legítimas, sejam elas de prestígio ou não.

Quanto às variedades, o livro afirma que há pessoas que usam "uma variedade da língua em que há regras de concordância convencionadas pela norma-padrão" e há pessoas que usam uma variedade da língua que nem sempre segue essas regras. Ele também comenta que as variedades urbanas são as consideradas mais prestigiadas e toma o cuidado de não confundir a variedade prestigiada com a norma-padrão. A norma-padrăo é definida pelo livro como "um modelo idealizado de língua" que corresponde a um "conjunto de regras veiculadas pela gramática normativa". Essa definição está de acordo com as teorias sociolinguísticas. Quanto à dinamicidade da língua, explica-se que "a língua passa por processos naturais de mudança e seu uso se modifica de acordo com a situação", podendo variar "conforme o tempo em que se vive, o lugar onde se mora, a idade, a circunstância em que a produzimos", entre outros (ARAÚJO, OLIVEIRA, 2018a, p. 88). 
Depois dessa primeira atividade mencionada, o subcapítulo adentra em um novo título chamado "linguagem formal e informal". Bagno (2013, p. 14) alerta que alguns livros didáticos, quando náo recorrem à dicotomia de certo e errado, trabalham com termos como informalidade e norma culta como disfarce para seguir impondo "formas linguísticas mais conservadoras". Portanto, nesse título ficamos atentos para a forma como o assunto seria abordado.

Novamente o título começa propondo uma atividade com base em um excerto da crônica "na escola". O enunciado da atividade afirma que nesse texto são encontradas "palavras e expressões que costumam ser usadas em situaçôes informais de comunicação". Então, abaixo do enunciado, destacam-se três frases utilizadas pelos personagens: "Uniforme é papo-furado. / Porque minissaia é muito mais bacana. / Ah, cada um na sua." (ARAÚJO, OLIVEIRA, 2018a, p. 88, grifo do autor). Pede-se que o aluno reflita e responda a quatro questôes.

A primeira questão é de resposta pessoal e pergunta se, na opinião do aluno, os termos destacados "foram empregados adequadamente pelos personagens na situação de comunicação" e por quê. Sobre essa questão, no manual em "U” há uma orientação afirmando ser esperado que os alunos "concluam que sim, pois os personagens encontram-se em uma situação informal de sala de aula". Ou seja, um contexto em que os alunos costumam se expressar em sua linguagem espontânea do dia a dia (ARAÚJO, OLIVEIRA, 2018a, p. 89).

A segunda questão supóe que o aluno estivesse "apresentando um trabalho sobre o uso do uniforme em um seminário organizado por várias escolas" e pergunta se, nesse caso, "seria adequado dizer 'uniforme é papo-furado" e por quê. Para a resposta, o livro indica que o aluno deve concluir que "náo", pois "a linguagem deve ser adequada aos interlocutores e à situação de comunicaçáo em que é empregada". Como um "seminário organizado entre várias escolas pressupóe um grau" maior de formalidade, "o uso de gírias seria inadequado" (ARAÚJO, OLIVEIRA, 2018a, p. 89).

A terceira questáo apresenta uma lista com quatro situaçóes de comunicação diferentes: "I. audiência com um juiz; II. Bate-papo com os amigos; III. Entrevista em programa de TV destinado ao público jovem; e IV. Entrevista de emprego". Pede-se que o aluno indique as situaçóes em que ele considera que seria "adequado empregar a expressáo 'papo-furado"”, justificando sua resposta. A resposta do livro afirma que "são adequadas as situações II e III, pois não exigem formalidade" (ARAÚJO, OLIVEIRA, 2018a, p. 89). Na quarta atividade, o aluno deve reescrever as frases destacadas acima utilizando uma linguagem mais formal.

Ao final dessa atividade, apresenta-se um quadro para definir os conceitos de linguagem formal e informal. No quadro, explica-se que, para adequar nossa linguagem à situaçáo de comunicação, "devemos considerar aspectos como o assunto tratado, o grau de intimidade, o tipo de relação entre falante/ouvinte e escritor/leitor, o lugar onde se está", entre outros. Assim, define-se a linguagem formal como uma linguagem "elaborada", de conteúdo geralmente "mais complexo e vocabulário técnico". Nela, "há maior preocupação com a norma-padrão" e ela 
deve estar "presente em situaçôes de maior formalidade". Já a linguagem informal é definida como "mais simples, espontânea" e com a possibilidade do uso de gírias. "É bastante usada com familiares" e pessoas que não exigem formalidade, sendo "adequada para a fala imediata e do dia a dia" (ARAÚJO, OLIVEIRA, 2018a, p. 89).

Sobre as atividades e os conceitos de linguagem formal e informal, é possível notar que o que está sendo buscado não é uma distinção do "certo" e do "errado", mas sim uma preparação do aluno para atuar em situaçóes de comunicação que vão exigir mais ou menos formalidade. Nas definiçôes dos dois termos, afirmar que a linguagem formal é complexa e a linguagem informal é simples talvez tenha sido uma escolha de palavras perigosa. Porém, compreende-se que o objetivo do livro não é privilegiar uma em detrimento da outra.

$\mathrm{Na}$ sequência propóe-se a última atividade do subcapítulo, desta vez baseada na seguinte charge:

Figura 1: charge para atividade sobre linguagem formal e informal.

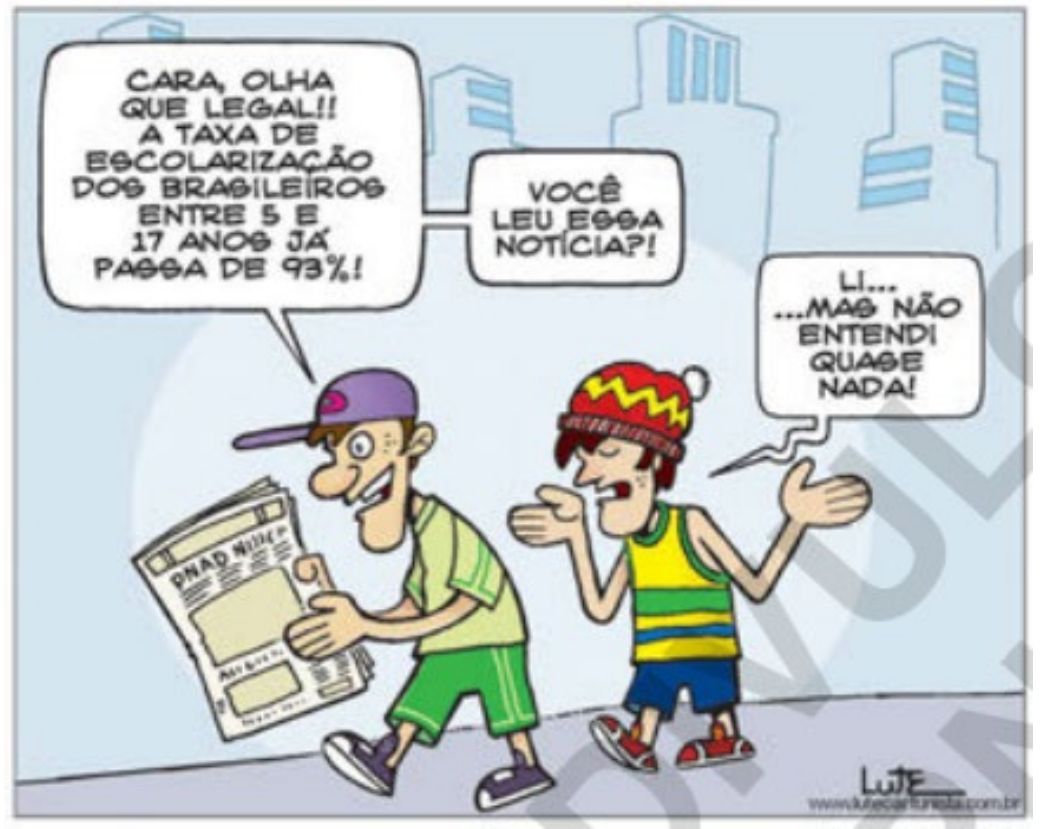

Fonte: ARAÚJO, OLIVEIRA, 2018a, p. 89.

$\mathrm{O}$ enunciado da atividade pede que se leia a charge acima para em seguida responder a três questôes. A primeira questão é apenas sobre a interpretação da charge, portanto sem relevância para esta análise. A segunda questáo pergunta se "a linguagem empregada pelo personagem que segura o jornal é formal ou informal" e pede que o aluno destaque palavras que justifiquem sua resposta. A resposta 
sugerida pelo livro é de que a linguagem utilizada é informal devido às palavras "cara" e "legal" (ARAÚJO, OLIVEIRA, 2018a, p. 90).

A terceira questão pergunta se "a situação comunicativa retratada" pela charge permite o uso desse tipo de linguagem. Na resposta sugerida pelo livro "esperase que os alunos respondam que sim", pois é uma situação em que "não há a necessidade de monitoramento linguístico, porque náo há formalidade", então é possível empregar a linguagem informal. Sobre essa terceira questão, no manual em "U" há uma orientação para que o professor "explique aos alunos que a linguagem é múltipla e variada e deve ser adequada ao contexto em que é empregada”. A charge caracteriza um contexto informal, portanto, "considerar que a charge apresenta termos e expressóes errados é agir com preconceito linguístico" (ARAÚJO, OLIVEIRA, 2018a, p. 90).

Essa orientação foi imprescindível para a qualidade da abordagem do livro sobre o assunto de formalidade e informalidade. Essa pequena observação foi o suficiente para garantir que o livro realmente náo recorre à dicotomia de "certo" e "errado", como temia Bagno (2013, p. 14). Ele recorre à intenção de instruir os alunos a compreenderem as diferentes situaçóes de comunicação, fazendo adaptaçóes quando necessário, mas sem deixar de usar sua própria variedade linguística sempre que possível. Conforme Coelho et al. (2015, p. 147), a escola deve "criar debates sobre a necessidade de adequação da linguagem às diferentes situaçóes de comunicação" e é exatamente isso que ocorre no título analisado.

\subsubsection{Capítulo 4: nossos relacionamentos}

No início do capítulo 4, o manual em "U" na lateral da página já informa que nele será trabalhada a habilidade da BNCC EF69LP56, que visa ensinar o aluno a "fazer uso consciente e reflexivo de regras e normas da norma-padrão em situaçóes de fala e escrita nas quais ela deve ser usada" (BRASIL, 2018, p. 161). Esse é um momento importante para analisar como os tópicos da norma-padrão são trabalhados dentro do livro. Bagno (2007, p. 135) afirma que "alguns livros didáticos parecem abordar a variação linguística" apenas pela necessidade de "cumprir as exigências do Ministério da Educação", o que resulta em livros com um capítulo tratando adequadamente desse tema e todo o resto tratando das questóes gramaticais de forma "conservadora e autoritária". Portanto, aqui cabe uma análise da habilidade mencionada.

Dentro desse capítulo, novamente no subcapítulo "reflexão sobre o uso da língua", são abordados os pronomes pessoais e de tratamento. Nos pronomes pessoais, apresenta-se a clássica tabela que relaciona as pessoas do discurso com os pronomes pessoais do caso reto e os pronomes pessoais do caso oblíquo. Felizmente, a abordagem do tópico não se restringe ao estabelecido pela norma-padrão. No manual em "U", uma orientação salienta que esse é um momento propício para que o professor aborde com a turma a "questão das variedades linguísticas regionais" e históricas (ARAÚJO, OLIVEIRA, 2018a, p. 109). Em relação às variedades linguísticas regionais, comenta-se que "em algumas regiōes do Brasil ainda se 
observa o uso do pronome pessoal 'tu', mesmo que o verbo náo concorde em pessoa com o pronome". Em relação à variedade linguística histórica, comenta-se que "o pronome 'vós' caiu em desuso". Dessa forma, é possível ressaltar para os alunos que seu uso ainda se observa em "textos mais arcaicos" (ARAÚJO, OLIVEIRA, 2018a, p. 109).

Ainda no ensino dos pronomes, uma atividade apresenta a frase "Só queria que você não deixasse bagunçado demais porque me incomoda" e pede que o aluno reescreva-a fazendo uso do pronome "nós". Em relação a isso, o manual em "U" sugere ao professor que mostre aos seus alunos "a diferença entre o português brasileiro formal e o português brasileiro informal no que se refere ao uso do pronome 'nós' e da expressão 'a gente'". Desse modo, faz-se uma retomada da linguagem formal e informal e de uma das variedades linguísticas do português brasileiro, que substitui o pronome "nós" por "a gente". (ARAÚJO, OLIVEIRA, 2018a, p. 112).

O fato de que as variedades linguísticas são lembradas durante o momento de aprendizagem da norma-padrão prova que o livro não isolou o tema nem o relegou a um mero capítulo, mas sim fez com que ele continuasse se fazendo presente dentro de outros contextos. Isso demonstra o caráter moderno e não autoritário da coleção. Porém, vale alertar que nesse subcapítulo a variação linguística está sendo mencionada apenas dentro do manual em "U" feito para o professor. Cabe ao professor a responsabilidade de ler a orientação e preparar uma aula que abarque o tema.

\subsubsection{Capítulo 6: construindo um mundo sustentável}

Nesse capítulo, apenas uma atividade de revisão e reescrita chama a atenção desta análise. No manual em "U", pede-se ao professor que conduza seus alunos a trocar suas produçóes textuais. Então o professor deve acompanhar a avaliação que os alunos realizarem. O manual orienta que o professor "informe aos alunos sobre a importância de respeitar a escrita dos colegas e não usar esse processo colaborativo de avaliação para ações discriminatórias e preconceituosas" (ARAÚJO, OLIVEIRA, 2018a, p. 193).

Essa orientação é relevante, pois demonstra a preocupação em defender o respeito também às variedades escritas. De acordo com Basso e Ilari (2012, p. 234), "a escola passa à sociedade a ideia de que escrever bem é escrever correto, e a sociedade cobra da escola que ensine a escrever correto, num movimento circular que é raramente quebrado". Porém, exatamente nessa atividade de reescrita, podemos ver que o livro didático preza pelo respeito não só das variedades faladas, mas também escritas.

\subsubsection{Capítulo 7: histórias que o povo conta}

No capítulo 7, assim como no capítulo 3, o manual em "U" informa que será trabalhada a habilidade EF69LP55 da BNCC. Retomando seu significado, essa 
habilidade busca ensinar o aluno a "reconhecer as variedades da língua falada, o conceito de norma-padrão e o de preconceito linguístico" (BRASIL, 2018, p. 161), sendo, portanto, uma habilidade essencial para esta análise.

Esse capítulo aborda o gênero textual causo. Segundo a definição dada pelo próprio livro didático (2018a, p. 199), "os causos são histórias de tradição oral geralmente contadas em uma linguagem espontânea, que registra o jeito de falar típico de determinada regiáo ou localidade". Portanto, características como sotaque e vocabulário regionais são naturais ao gênero. Dessa forma, na linguagem desse tipo de texto é possível encontrar variedades linguísticas que o livro didático precisa apresentar aos alunos. O primeiro causo trabalhado chama-se "dois caboclos na enfermaria", de Rolando Boldrin. Nele, dois caboclos vão consultar-se com um médico por causa de uma dor na perna. No texto, os caboclos utilizam uma variedade linguística, enquanto o médico utiliza outra. Para ilustrar a linguagem utilizada pelos caboclos, alguns excertos foram destacados abaixo:

- $\hat{\mathrm{E}}$, compadre. Nóis véve sofrendo muito com a danada dessa dor na perna... Por que é que nóis num vamos junto no dotô? Vamos lá. A gente faz a consulta, tal, se interna no mesmo quarto... Daí fazemo o tratamento e vemo o que acontece. Se curar, tá bom demais!

[...]

Caboclo 1 - Mas cumpadi, a minha perna doeu demais da conta com os aperto do hómi... Como é que a sua não doeu nadica de nada?!

Caboclo 2 - E ocê acha que eu vou dá a perna que dói pro hómi apertá?!?!?! (ARAÚJO; OLIVEIRA, 2018a, p.197-198, grifo nosso)

Após as questôes de interpretação de texto, inicia-se um título chamado "linguagem do texto", em que a habilidade EF69LP55 está sendo trabalhada. Nele, propóe-se uma atividade com quatro questóes. O manual em "U" alerta que "essa atividade enfoca a escolha lexical geralmente utilizada nos causos e representa algumas variedades faladas da língua". Sendo assim, o manual orienta ao professor que "chame a atenção dos alunos para os diferentes papéis sociais assumidos pelos personagens e as variedades linguísticas empregadas em decorrência desses papéis" (ARAÚJO, OLIVEIRA, 2018a, p. 199).

$\mathrm{O}$ enunciado da atividade afirma que entre os diálogos dos caboclos e o diálogo do médico há a representação de uma forma diferente dos modos de falar. Entáo, pede que se responda a quatro questóes. A primeira questáo pergunta "qual variedade linguística é usada para representar o modo de falar dos caboclos". A resposta esperada pelo livro é de que os alunos reconheçam que essa é "alguma variedade regional do português brasileiro" (ARAÚJO, OLIVEIRA, 2018a, p. 199). A segunda questáo pergunta "que efeito de sentido o uso dessa variedade linguística na fala dos caboclos pode provocar". Uma das possíveis respostas, segundo o livro, é de que "o modo de falar possibilita caracterizar melhor os personagens e inferir seus valores humanos e sociais".

A terceira questão é um pouco semelhante à primeira: pergunta-se "qual é a variedade linguística usada para representar o modo de falar do médico". De 
acordo com o livro didático, a resposta esperada é que os alunos reconheçam que "o modo de falar do médico emprega a variedade urbana de prestígio, de acordo com a norma-padrão da língua”. Nota-se que essa passagem parece contradizer a definição dada anteriormente de que norma-padrão seria "um modelo idealizado de língua" (ARAÚJO, OLIVEIRA, 2018a, p. 88). Nesse caso, seria mais adequado que o livro didático substituísse a expressão de acordo pela expressão que tenta se aproximar da norma-padrão da língua. Aparentemente, o intuito dessas duas questôes é que o aluno perceba as diferenças entre a variedade regional e a variedade urbana prestigiada (ARAÚJO, OLIVEIRA, 2018a, p. 200).

A última questão pergunta "que efeito de sentido o uso dessa variedade linguística na fala do médico pode provocar". Para esse caso, o livro náo sugere nenhuma resposta possível, deixando a reflexão a cargo dos alunos. Essa é uma questáo delicada, pois alguns alunos podem pensar que o médico estudou mais, está em uma classe social de prestígio e por isso fala "melhor" ou fala "certo". Porém, o manual em "U" observa ser esperado dos alunos que "respondam que o médico está em uma situação de trabalho e, em decorrência disso, usa a norma-padráo, mesmo que esteja ou pertença à mesma região dos pacientes" (ARAÚJO, OLIVEIRA, 2018a, p. 200, grifo nosso). Nessa passagem, nota-se a mesma contradição já vista no parágrafo anterior. Se a norma-padrão é um modelo ideal que "não é a língua de ninguém" (BAGNO, 2007, p. 131), o médico não pode usá-la. O que o médico está utilizando é a norma culta urbana e letrada. Quanto à atividade, o professor deve estar atento às respostas dos alunos e às orientaçóes do manual, sendo assim capaz de estabelecer uma relação entre ambos e garantir o máximo aproveitamento dos recursos disponíveis.

$\mathrm{Na}$ sequência, inicia-se uma seção chamada "trocando ideias". O manual em "U" afirma que o objetivo dessa seção é "criar um momento para os alunos trocarem ideias sobre as variedades linguísticas e o preconceito linguístico, com base na leitura do causo". Para essa seção, são propostas quatro atividades. Para conversar sobre as atividades, o livro sugere que a turma se organize em um círculo. A primeira atividade afirma em seu enunciado que no texto "dois caboclos na enfermaria", o autor "busca representar, nas falas dos caboclos, o falar caipira, jeito de falar próprio de certas regiôes do interior do estado de São Paulo" (ARAÚJO, OLIVEIRA, 2018a, p. 200). Seguem-se duas questóes para essa atividade.

A primeira questão pergunta se, na opinião pessoal do aluno, "o falar caipira pode ser considerado incorreto" e por quê. Não há sugestão de resposta pelo livro porque a resposta deve ser pessoal. No manual em " $U$ " há uma orientação sobre essa questáo que diz se esperar dos alunos que "compreendam que o falar caipira é uma variedade da língua e não um erro". Cabe ao professor conversar sobre os temas propostos pelo manual em "U", abordando as variedades linguísticas e o preconceito linguístico. A segunda questão pergunta se "as falas dos caboclos produziriam o mesmo efeito de sentido se fossem transpostas para a variedade urbana". O livro sugere como possível resposta que não, pois "o causo perderia sua originalidade e os personagens ficariam bastante descaracterizados" (ARAÚJO, OLIVEIRA, 2018a, p. 200). 
A segunda atividade pergunta se o aluno acha que "um contador de causo nordestino ou gaúcho contaria essa história da mesma maneira" e por quê. A resposta é pessoal, mas o manual em "U" complementa dizendo esperar que os alunos respondam que náo seria contado da mesma forma, pois, mesmo o causo contendo "algumas expressōes usadas de maneira semelhante por esses falantes, as variedades regionais, o sotaque e o jeito de se expressarem seriam diferentes". A terceira atividade reforça com o aluno a importância dos gestos, da entonação da voz, do jeito de olhar e outras linguagens náo verbais para a contação de causo, pois "reforçam a língua oral" (ARAÚJO, OLIVEIRA, 2018a, p. 200).

A atividade quatro traz um enunciado muito interessante, em que se pergunta se "todas as expressões da fala dos caboclos são empregadas apenas no falar caipira". Após o enunciado, destacam-se duas frases do causo: "Daí fazemo o tratamento e vemo o que acontece" e "E ocê acha que eu vou dá a perna que dói pro hómi apertá?!?!??" (ARAÚJO; OLIVEIRA, 2018a, p. 200, grifo do autor). Três questóes complementam a reflexáo do enunciado acima. A primeira questáo pergunta se alguma dessas palavras faz parte do jeito de falar do próprio aluno. Sobre isso, o manual em "U" orienta que, "ainda que os alunos afirmem que essas palavras não fazem parte do jeito de eles falarem, espera-se que percebam que a supressão do " $\mathrm{r}$ " final e a redução de palavras como "você" para "cê" e "está" para "tá" é comum na fala dos brasileiros" (ARAÚJO, OLIVEIRA, 2018a, p. 200).

A segunda questão afirma que "quando conversamos é comum não pronunciarmos o ' $\mathrm{r}$ ' nem o 's' finais ou cortarmos parte das palavras", como nos exemplos "aperta" em vez de "apertar" e "fazemo" em vez de "fazemos". Pergunta-se por qual motivo o aluno acha que isso acontece. De acordo com o manual, espera-se que os alunos notem que "na língua falada (principalmente em situaçóes informais) é comum não pronunciar todos os fonemas das palavras" (ARAÚJO, OLIVEIRA, 2018a, p. 200). O interessante dessas questóes é fazê-los perceberem que algumas das palavras utilizadas no causo como variedade linguística regional também são utilizadas nas variedades urbanas.

A última questão pergunta a opinião do aluno sobre "por que as pessoas têm preconceito com quem fala variedades diferentes das urbanas" e "como o preconceito pode ser combatido". Segundo o manual, "espera-se que os alunos enfatizem o respeito às diferenças", percebendo que "o diferente não é errado, mas sim a manifestação da diversidade cultural, social e histórica do povo brasileiro" (ARAÚJO, OLIVEIRA, 2018a, p. 200).

Por fim, o manual fornece algumas orientaçôes para o professor seguir durante essa aula. Sugere-se que ele "enfatize para os alunos a importância do combate ao preconceito linguístico" e retome o que é e quais são as variedades linguísticas. Caso o professor queira, propóe-se que ele peça aos alunos que "pesquisem sobre essas variedades". Ao professor que queira compreender um pouco mais sobre os conceitos da variação linguística, sugere-se que ele consulte o Glossário Ceale. Além disso, pede-se que o professor verifique, durante a roda de conversa, "se os alunos apresentam falas preconceituosas em relaçáo às variedades regionais". Caso isso 
aconteça, é aconselhado ao professor "fazer intervençóes por meio de perguntas e exemplos e colocar a discussão em pauta para que os alunos reconheçam a presença de preconceito linguístico e compreendam como isso é prejudicial à sociedade como um todo" (ARAÚJO, OLIVEIRA, 2018a, p. 200).

Mais adiante, nesse mesmo capítulo, aparece outro causo. Dessa vez, de autoria de Mario Quintana, intitulado "aquele animal estranho". O causo realça a variedade linguística dos moradores do interior do Rio Grande do Sul. Novamente uma parte do livro se destina à "linguagem do texto" para trabalhar a habilidade EF69LP55. Dessa vez, propóe-se duas atividades: a primeira sobre a variaçáo linguística e a segunda sobre as onomatopeias presentes no causo. Falaremos aqui somente da primeira atividade, conforme o escopo da análise. Nela, pede-se que o aluno releia os seguintes trechos retirados do causo: "[...] eles o mataram a pau [...]", "Ia um piazinho estrada fora no seu petiço [...]", "O povo se afastou, resfolegante [...]", "A la pucha! - exclamou entáo um guasca, entre espantado e penalizado - o animal deu cria!" (ARAÚJO; OLIVEIRA, 2018a, p. 210, grifo do autor).

Em seguida, o aluno deve responder a duas questóes. A primeira questão pergunta como o aluno "comunicaria as mesmas ideias expressas pelos termos destacados utilizando expressões típicas" da sua própria região. A resposta é pessoal. A segunda questáo pergunta "se o texto fosse transcrito utilizando uma variedade urbana, de acordo com a norma-padráo da língua, teria criado os mesmos efeitos de sentido na leitura do causo?". Novamente chamamos atenção para a expressão "de acordo" utilizada pelo livro didático para relacionar variedade urbana com norma culta, por não ser a expressão mais adequada. Quanto à possível resposta para a atividade, o livro indica que náo, pois essas expressóes "representam os falares dos moradores dos pampas gaúchos" e "contribuem para caracterizar os personagens e para a construção da compreensão geral do causo" (ARAÚJO, OLIVEIRA, 2018a, p. 210). Uma questáo semelhante já havia sido proposta no causo anterior, sobre os caboclos.

O manual em " $U$ " informa que essa atividade chama os alunos a refletirem "sobre as variedades da língua falada e a decorrente produção de efeitos de sentido para a caracterização dos personagens e da cena”. Sendo assim, orienta-se que o professor ajude os alunos a compreenderem "que o uso da representação da variedade linguística própria do povo gaúcho não foi aleatório", mas sim uma "escolha do autor para colaborar na constituição dos sentidos do texto" (ARAÚJO, OLIVEIRA, 2018a, p. 211). Essa noção do uso da variedade linguística como recurso textual aparece novamente, nesse mesmo capítulo, um pouco mais adiante quando se trabalha a literatura de cordel.

Nesse caso, são apresentados dois poemas para os alunos: "A história da literatura de cordel", de Abdias Campos; e "O boi zebu e as formigas", de Patativa do Assaré. Dentre as várias atividades propostas sobre a literatura de cordel, uma se relaciona ao tópico de variaçáo linguística. $\mathrm{O}$ enunciado da atividade pergunta: "nos dois poemas, há palavras que caracterizam o modo de falar de determinada região brasileira (variedade regional)? Transcreva exemplos" (ARAÚJO; OLIVEIRA, 
2018a, p. 219). A resposta sugerida pelo livro é de que "apenas no poema 'o boi zebu e as formigas' o poeta representa o modo de falar do sertanejo, usando uma variedade linguística regional". Algumas palavras destacadas pelo livro como exemplos foram "moiadinho", "suó", "cuchilă", "juazêro", "riba", "formiguêro", "trabaiando", "veve", "inzempro" (ARAÚJO; OLIVEIRA, 2018a, p. 219).

O manual em "U" afirma que "essa atividade tem como objetivo verificar o tipo de linguagem usada nos dois poemas e reconhecer a variedade da língua falada nos textos". Orienta-se que o professor ajude os alunos a encontrar no poema "O boi zebu e as formigas" as palavras de exemplo e informe-os de que elas "são parecidas com o modo de falar dos habitantes do sertão brasileiro". Também se orienta ao professor que, se possível, apresente aos alunos vídeos com a "declamaçáo ou cantoria dos poemas de Patativa do Assaré” (ARAÚJO; OLIVEIRA, 2018a, p. 219).

Ao final desse capítulo, na seção "produção de texto", propóe-se uma atividade em que os alunos devem formar grupos e buscar alguém na família, vizinhança (ou na internet, se necessário), que conte um causo para eles. Depois, os alunos devem recriar um texto a partir dos causos ouvidos. Nas orientaçóes da atividade, os alunos são relembrados de que podem "representar por escrito as palavras e expressóes usadas pelos personagens ou pelos próprios contadores" na modalidade oral da língua em conversaçóes espontâneas (ARAÚJO; OLIVEIRA, 2018a, p. 220). Essa atividade parece relevante para que os alunos observem com mais atenção as características da variedade linguística de sua comunidade (ou do contador do causo).

\subsubsection{Capítulo 8: diversidade cultural}

No capítulo 8 , o tema da variação linguística não se faz tão frequentemente presente quanto nos capítulos analisados até o momento. Mas uma atividade em específico se demonstra bastante relevante para o tema. Esse capítulo trabalha o gênero textual notícia, e a notícia selecionada pelo livro apresenta uma entrevista com transcriçóes de fala das pessoas entrevistadas. Com isso, uma das atividades sobre esse gênero destaca alguns trechos dessa entrevista para a análise dos alunos: "Já a paraense Auricélia Amaral, torcedora do Garantido, vai assistir pela primeira vez ao festival", "O Caprichoso esse ano vai ser campeão", "Eu não tenho dúvida de que a gente vai lotar o bumbódromo e muita gente vai ficar de fora porque a capacidade do bumbódromo é restrita [...]", "O Caprichoso vai entrar na arena do Bumbódromo por volta de meia-noite e meia, encerrando às $3 \mathrm{~h}$ da madrugada" (ARAÚJO; OLIVEIRA, 2018a, p. 238, grifo do autor).

Sobre esses trechos destacados, a atividade propóe duas questôes. A primeira questáo pergunta ao aluno quais "formas verbais substituiriam as locuçóes verbais em destaque expressando o tempo futuro do presente do indicativo". As respostas seriam "assistirá", "será", "lotará", "ficarâ" e "entrará". A segunda questâo pede que o aluno "converse com o professor e os colegas" e responda o provável motivo por que "optou-se pela locução verbal para expressar o tempo futuro, em vez do uso do verbo no futuro do presente". A resposta sugerida pelo livro é de que "a locução verbal é 
mais informal, mais usada no dia a dia do que o verbo no futuro do presente". No manual sugere-se que, ao corrigir essa atividade, o professor "retome com os alunos o conceito de variedade linguística" e ressalte que, em situaçóes informais, as pessoas são mais "espontâneas" e geralmente empregam "estruturas mais comuns ou usuais” (ARAÚJO; OLIVEIRA, 2018a, p. 238).

\subsection{Sétimo a nono ano}

A fim de não estender demais o artigo, as análises dos livros didáticos de sétimo, oitavo e nono ano dessa coleção foram sintetizadas e reunidas dentro deste mesmo subtítulo. Seguindo a ordem, vamos iniciar com uma breve análise geral do livro de sétimo ano. As habilidades EF69LP55 e EF69LP56 da BNCC também são trabalhadas nesse livro. Além disso, conceitos já vistos no livro de sexto ano são revisados, como as situaçóes formais e informais de fala, as variedades linguísticas do português brasileiro e o combate ao preconceito linguístico. Em adição a isso, parte do livro se dedica a levar os alunos a identificar os efeitos de sentido do uso de expressões, jargões e gírias, levando em consideração a variação. Inclusive, no manual em "U", encontram-se indicaçóes de materiais de leitura sobre a variação linguística para que o professor possa se aprofundar mais no assunto.

Ainda sobre o livro de sétimo ano, cabe destacar o capítulo dois, em que a ortografia é trabalhada de forma bastante sensível. Uma questão apresenta aos alunos um quadro com as seguintes palavras: "viagem, trajeto, estrangeiro, viajem, refugiado e jipe". A atividade pede que os alunos leiam as palavras e respondam a três questóes. A primeira questáo pergunta ao aluno "o que essas palavras têm em comum em relação à sonoridade”. A resposta se refere as letras 'g' e 'j', que "seguidas das vogais 'e' e ' $\mathrm{i}$ ' possuem o mesmo som". A segunda questão pede que o aluno escreva mais "cinco palavras que apresentem a mesma característica" observada anteriormente. A terceira questão pede que o aluno "pesquise e explique a diferença entre viagem e viajem". Essas duas últimas questôes são de resposta pessoal, mas o manual em "U" sugere algumas respostas possíveis. A sugestão para a terceira questão é que "espera-se que os alunos respondam que viagem é substantivo e viajem é um verbo no presente do subjuntivo". É interessante observar como essa atividade não menciona o uso "correto" ou "errado" dessas palavras, mas sim busca explicitar aos alunos a semelhança entre os sons e as diferenças entre as grafias, buscando explicar os usos adequados para cada uma (ARAÚJO; OLIVEIRA, 2018b, p. 81).

No livro de oitavo ano, as habilidades da BNCC de oitavo a nono ano começam a aparecer. Com isso, o espaço destinado às habilidades de sexto a nono ano é reduzido. A habilidade EF69LP55 náo aparece em nenhum momento do livro. A habilidade EF69LP56 aparece pouco, nos momentos de ensino da normapadrão. Nesse aspecto, o livro não perde em qualidade, pois continua apresentando as regras gramaticais de forma respeitosa, sem definir um certo e um errado. Em uma proposta de trabalho de pesquisa sobre gírias, as variedades linguísticas são relembradas. O manual em "U" sugere que o professor aproveite a "atividade para falar com os alunos sobre a legitimidade das diferentes variedades linguísticas 
faladas no Brasil, além de debater com eles a questão da adequação da variedade às situaçóes comunicativas" (ARAÚJO; OLIVEIRA, 2018c, p. 38).

Por fim, no livro de nono ano, a habilidade EF69LP55 volta a aparecer. Da mesma forma, a habilidade EF69LP56 também aparece. Porém, nesse livro, elas aparecem pouco, apenas em um ou dois capítulos no livro inteiro. O capítulo 6, intitulado "as várias faces do preconceito", destina-se a tratar dos diferentes tipos de preconceito existentes. Nesse capítulo, no subtítulo "hora da pesquisa", o livro didático propóe que os alunos realizem uma pesquisa sobre o preconceito na língua. Nas instruçôes da atividade, pede-se que o aluno pesquise "as diferentes variaçóes do português oral do Brasil", seus dialetos e depoimentos de preconceitos linguísticos a fim de "criar um vídeo-minuto para divulgar os dados" da pesquisa (ARAÚJO; OLIVEIRA, 2018d, p. 178). No capítulo 7, em que a habilidade EF69LP55 está sendo trabalhada, é apresentado um excerto de um texto escrito em português de Portugal. A partir disso, uma atividade pede que os alunos identifiquem e comparem "as variedades faladas em Portugal e no Brasil" (ARAÚJO; OLIVEIRA, 2018d, p. 202).

\section{Consideraçóes Finais}

Com os resultados da análise expostos acima é possível dizer que o objetivo proposto por este trabalho - realizar uma análise sobre uma coleção de livros didáticos para Ensino Fundamental a fim de avaliar a presença de conteúdos relacionados à variação linguística - foi atingido. A partir da análise realizada, podemos concluir que a coleçáo selecionada apresenta boa qualidade em termos de abordagem da variação linguística. Nessa coleção, o assunto é trabalhado em todos os livros e não apenas em um capítulo específico para cumprir com os requisitos do MEC. Além disso, as regras gramaticais não são abordadas de forma "conservadora e autoritária" (BAGNO, 2007, p. 135).

Em nenhum momento o livro defende conceitos a partir de uma visão do "certo" e do "errado". No máximo, o livro indica os tratamentos mais adequados às situações de fala formais e informais, que são sempre mencionadas. Um exemplo de abordagem da coleção em relação a esse aspecto é a orientação apresentada no manual em "U" do livro de nono ano, em que se diz: "comente com os alunos que, embora a linguagem seja informal, devem-se respeitar as regras de concordância verbal e nominal, o uso da pontuaçáo, a ortografia adequada e as regências verbal e nominal" (ARAÚJO; OLIVEIRA, 2018d, p. 210).

Um ponto negativo encontrado na coleção é a confusão em relação às definiçôes de norma culta e norma-padrão. Embora no livro de sexto ano seja feita uma definição desses dois termos que vai ao encontro do que é defendido pelas teorias sociolinguísticas, logo adiante, nesse mesmo livro, assim como nos próximos, a norma culta é confundida com a norma-padrão. Nessa confusão, o livro dá a entender que a norma culta estaria de acordo com a norma-padrão, ou que, ao usar a norma culta, o falante estivesse usando a norma-padrão. Dessa forma, o livro 
didático acaba contradizendo até mesmo a sua própria definição do que seria cada uma dessas normas.

Apesar disso, é possível afirmar que a coleção analisada demonstra preocuparse com o tratamento da variação linguística e busca trabalhar o assunto em todos os anos finais do Ensino Fundamental. A fim de apresentar uma avaliação geral da presença de conteúdos relativos à variação linguística na coleção, foi desenvolvida a tabela abaixo, com base no roteiro de análise de livros didáticos elaborado por Bagno (2007, p. 125-139). Na linha que se refere à separaçáo entre norma culta e norma-padrão, marcaram-se ambas as opçóes "sim" e "não", pois, apesar de definir os termos de forma separada, o livro confunde-os. Cabe ressaltar que cada um desses critérios foi analisado a partir de impressóes pessoais.

\begin{tabular}{|l|c|c|}
\hline A coleçáo de livros didáticos abordou: & Sim & Não \\
\hline A pluralidade de línguas que existe no Brasil & & $\mathbf{x}$ \\
\hline As variantes características das variedades prestigiadas & & $\mathbf{x}$ \\
\hline Variedades prestigiadas e estigmatizadas & $\mathbf{x}$ & \\
\hline A separação entre norma culta e norma-padrão (apresenta divergências) & $\mathbf{x}$ & $\mathbf{x}$ \\
\hline Variaçóes de sotaques, dialetos e léxico & $\mathbf{x}$ & \\
\hline Variações em fenômenos gramaticais & $\mathbf{x}$ & \\
\hline Usou termos como "certo" e "errado" & & $\mathbf{x}$ \\
\hline Usou termos como "adequado" e "inadequado" & $\mathbf{x}$ & \\
\hline Usou termos como "formal" e "informal” & $\mathbf{x}$ & \\
\hline A variação entre fala e escrita & $\mathbf{x}$ & \\
\hline O fenômeno da mudança linguística - sincronia e diacronia & $\mathbf{x}$ & \\
\hline
\end{tabular}

\section{Referências}

ARAÚJO, Lucy Aparecida Melo; OLIVEIRA, Tânia Amaral. Tecendo Linguagens: língua portuguesa: $6^{\circ}$ ano. 5 ed. Barueri: IBEP, 2018a.

ARAÚJO, Lucy Aparecida Melo; OLIVEIRA, Tânia Amaral. Tecendo Linguagens: língua portuguesa: $7^{\circ}$ ano. 5 ed. Barueri: IBEP, $2018 \mathrm{~b}$.

ARAÚJO, Lucy Aparecida Melo; OLIVEIRA, Tânia Amaral. Tecendo Linguagens: língua portuguesa: $8^{\circ}$ ano. 5 ed. Barueri: IBEP, 2018c.

ARAÚJO, Lucy Aparecida Melo; OLIVEIRA, Tânia Amaral. Tecendo Linguagens: língua portuguesa: $9^{\circ}$ ano. 5 ed. Barueri: IBEP, 2018d.

BAGNO, Marcos. Nada na língua é por acaso: por uma pedagogia da variação linguística. São Paulo: Parábola Editorial, 2007. 
BAGNO, Marcos. Sete erros aos quatro ventos: a variação linguística no ensino de português. São Paulo: Parábola Editorial, 2013.

BASSO, Renato; ILARI, Rodolfo. O português da gente: a língua que estudamos, a língua que falamos. São Paulo: Contexto, 2012.

BELINI, Raimunda Gomes de Carvalho; SOUSA, Maria Margarete Fernandes de. A variação linguística no livro didático: um olhar sob a perspectiva sociolinguística. (Con) textos Linguísticos, Vitória, v. 8, n. 10, p. 211-230, 2014.

BNCC: construindo um currículo de educação integral. Instituto Ayrton Senna, 2020. Disponível em: https://institutoayrtonsenna.org.br/pt-br/BNCC/o-que-eBNCC. html\#: - :text=A\%20Base\%20Nacional\%20Comum\%20Curricular,pleno\%20de\%20 todos\%20os\%20estudantes. Acesso em: 18 fev. 2021.

BRASIL. Ministério da Educação. Base Nacional Comum Curricular. Brasília, 2018 COELHO, Izete Lehmkuhl et al. Para conhecer sociolinguística. São Paulo: Contexto, 2015.

ZILLES, Ana Maria; FARACO, Carlos Alberto. Para conhecer norma linguística. São Paulo: Contexto, 2017. 